\title{
Implementasi Alat Pendeteksi Getaran Bantalan Motor Induksi Pada Pabrik Menggunakan Sensor Piezoelektrik Berbasis SMS
}

\author{
Indra Roza, Ahmad Yanie, Agus Almi, Lisa Andriana \\ Teknik Elektro, Konsentrasi Energi Listrik, Fakultas Teknik dan Komputer \\ Universitas Harapan Medan \\ Jl. HM. Joni No.70C, Kota Medan, Telp. +62617366804, Sumatera Utara 20217 \\ e-mail: indraroza.ir@gmail.com
}

\begin{abstract}
Abstrak - Motor induksi dipabrik digunakan sebagai pengerak berbagai beban dengan rpm dan daya bervariasi. Motor beroperasi menimbulkan getaran, bantalan digunakan berfungsi untuk meredam getaran. Getaran tidak diizinkan akan menimbulkan kerusakan dan kegagalan motor. untuk mendeteksi getaran sebuah motor induksi dengan menyentuh/meraba tidak efektif. Adanya Alat pendeteksi getaran pada bantalan motor induksi dengan metode sensor piezioelektrik yang sensitive berbasis sms, mengunakan komponen elektronik seperti IC, Kapasitor, Resistor, Sensor Piezoelektrik dan Atmega 8 yang di program dengan catu daya 12 volt dan 5 volt. Sensor Piezoelektrik diletakkan pada body luar rumah bantalan untuk mendeteksi getaran yang proses dan dikalibrasi Atmega 8 ke Modem GSM mengirimkan sms kepada Operator Maintenance. Pengujian alat deteksi getaran menggunakkan tiga motor induksi dengan kapasitas daya motor $1440 \mathrm{rpm}(11 \mathrm{Kw}), 2930 \mathrm{rpm}(15 \mathrm{Kw})$ dan $3550 \mathrm{rpm}(22 \mathrm{Kw})$ Hasil nilai getaran yang telah dideteksi oleh sensor piezoelektrik pada motor induksi dengan kapasitas daya $11 \mathrm{kw}(1440 \mathrm{rpm})$ nilai getarannya $327 \mathrm{~Hz}$ umur bantalan 6 bulan dan $746 \mathrm{~Hz}$ umur bantalan 11 bulan, hasil nilai getaran pada motor induksi dengan kapasitas daya $2930 \mathrm{rpm}(15 \mathrm{~kW})$ nilai getarannya $478 \mathrm{~Hz}$ umur bantalan 6 bulan dan $895 \mathrm{~Hz}$ umur bantalan 12 bulan, dan Untuk hasil nilai getaran pada motor induksi kapasitas daya $3550 \mathrm{rpm}(22 \mathrm{~kW})$ nilai getarannya $562 \mathrm{~Hz}$ umur bantalan 7 bulan dan $1023 \mathrm{~Hz}$ umur bantalan 12 bulan. Getaran pengujian pada masing-masing motor induksi yang dikirim melalui sms dalan keadaan aman.
\end{abstract}

Kata kunci : Pendeteksi Getaran, Bantalan Motor, Kontroler Atmega 8, Modem GSM, Sensor Piezoelektrik

\begin{abstract}
The induction motor in the factory is used as a propeller of various loads requiring varying rpm and power. The motor operates to cause vibrations, the bearings used to dampen vibrations. Vibration not allowed will cause damage and motor failure. to detect the vibration of an induction motor by touching / feeling ineffectively. The existence of a vibration detection device on an induction motor bearing by the method of sensitive piezioelectric sensor based on SMS, using electronic components such as ICs, Capacitors, Resistors, Piezoelectric Sensors and Atmega 8 programmed with a 12 volt and 5 volt power supply. Piezoelectric sensors are placed on the body outside the bearing housing to detect vibrations that are processed and calibrated Atmega 8 to the GSM Modem sending an SMS to the Maintenance Operator. Testing of vibration detection devices using three induction motors with motor power capacity of $1440 \mathrm{rpm}(11 \mathrm{Kw}), 2930 \mathrm{rpm}(15 \mathrm{Kw})$ and $3550 \mathrm{rpm}(22 \mathrm{Kw})$ The results of vibration values that have been detected by piezoelectric sensors on induction motors with $11 \mathrm{kw}(1440 \mathrm{rpm})$ power capacity) vibration value $327 \mathrm{~Hz}$ bearing age 6 months and $746 \mathrm{~Hz}$ bearing life 11 months, the results of the vibration value on the induction motor with a capacity of $2930 \mathrm{rpm}(15 \mathrm{~kW})$ vibration value $478 \mathrm{~Hz}$ bearing age 6 months and $895 \mathrm{~Hz}$ bearing age 12 months, and for the results of the vibration value on the induction motor power capacity of $3550 \mathrm{rpm}(22 \mathrm{~kW})$ the vibration value is $562 \mathrm{~Hz}$ bearing age 7 months and $1023 \mathrm{~Hz}$ bearing age 12 months. Vibration testing on each induction motor that is sent via sms in a safe state.
\end{abstract}

Keywords: Vibration Detector, Motor Bearing, Atmega 8 Controller, GSM Modem, Piezoelectric Sensor

\section{PENDAHULUAN}

Untuk mendeteksi getaran pada motor dipabrik adalah menyentuh/meraba bekerja dengan baik atau tidak. Cara tidak efektif karena mengandalkan indera manusia yang dipengaruhi oleh perasaan dan emosi, untuk mengatasi salah satu permasalahan perawatan tersebut, dikembangkan metode mendeteksi getaran pada bantalan motor induksi menggunakkan sensor getar.

Mendeteksi getaran pada bantalan motor induksi merupakan salah satu cara efektif dalam perawatan kondisi motor induksi. tingkat getaran dideteksi mengindikasikan tingkat gangguan yang terjadi, semakin tinggi nilai getaran yang dideteksi indikasi adanya gangguan, kemungkinan sebuah kerusakan atau bahkan kegagalan motor. Banyak alat untuk 
mendeteksi getaran pada bantalan motor induksi telah dibuat dengan keunggulan masing-masing. Alat ini kembangkan untuk sistem deteksi getaran pada bantalan motor induksi berbasis sms, dengan memanfaatkan sensor getar yang sensitive.

Motor Induksi terdiri atas dua komponen utama yaitu bagian yang diam yang disebut stator dan bagian yang berputar yang disebut rotor. Rotor dan stator dipisahkan oleh celah udara (air gap) yang kecil dengan jarak antara $0,4 \mathrm{~mm}-4 \mathrm{~mm}$, tergantung daya output motor. Stator terdiri atas rangka/bingkai baja yang berlubang, inti besi silinder yang dibuat berlaminasi dan sejumlah slot yang dibuat untuk menampung belitan stator. Secara mekanis rangka menyangga rotor stator dan bearing. Belitan stator terdiri atas belitan belitan yang terbagi tiga secara seimbang yang terdistribusi dalam slot stator dan dihubungkan dengan sumber tegangan. Energi untuk rotor dihantarkan secara induksi oleh rotasi sinkron dari medan magnetik stator disebut motor induksi. Rotor merupakan elemen yang berputar, pada rotor terdapat kutub magnet dengan belitan kawatnya yang dialiri arus. Sedangkan bantalan (bearing) pada kedua sisi poros rotor berfungsi agar rotor dapat berputar bebas di dalam stator.

Bantalan adalah pendukung gerakan pada poros yang sangat besar perannya dalam operasi kerja motor induksi. Seperti yang telah disebutkan sebelumnya bahwa setiap desain motor induksi memiliki spesifikasi dalam bentuk dan posisi masing- masing komponen. Demikian halnya dengan bantalan, banyak sekali desain motor induksi yang meletakkan bantalan pada berbagai posisi, hal ini disesuaikan dengan fungsi utamanya yaitu mendukung gerakan relatif poros. Bantalan digunakan untuk mendukung gerakan relatif diantara komponen mesin dan motor induksi dan memungkinkan berbagai posisi pada masing-masing komponen tersebut. bearing atau bantalan adalah salah satu jenis bantalan yang memungkinkan gerakan relatif secara radial pada sumbu geraknya. Elemennya terdiri dari bola, pemisah / pemegang bola (cage), lintasan dalam (inner race), lintasan luar (outer race).

Vibrasi motor adalah gerakan yang berulang-ulang dengan tempo yang cepat pada motor, Pada posisi netral (neutral position) maka pegas akan merenggang untuk mengimbangi beban. Jika pegas ini diberi gaya seketika dengan menariknya beban misalkan pada posisi bawah (lower position) kemudian langsung dilepaskan akan membuat beban bergerak bolak-balik dari posisi bawah menuju posisi atas dan setarusnya guna mengimbangi gaya seketika tersebut. Gerakan dari beban yang bergerak bolak-balik akan membentuk sebuah gelombang dengandomain waktu. Secara istilah, vibrasi motor (Vibration of Motor) diartikan sebagai gerakan bolak-balik dari motor secara utuh atau komponen mekanik motor sebagai reaksi dari adanya gaya yang mempengaruhinya baik itu gaya dalam maupun gaya luar. Kasus yang dominan terjadi dalam vibrasi motor adalah yang disebabkan oleh gaya eksitasi yang berasal dari motor itu sendiri. Sensor getaran merupakan salah satu sensor yang dapat mengukur getaran suatu benda yang nantinya dimana data tersebut akan diproses untuk kepentingan percobaan ataupun digunakan untuk mengantisipasi sebuah kemungkinan adanya bahaya. Salah satu jenis sensor getaran yang saat ini sering digunakan adalah. Accelerometer adalah sebuah alat yang berfungsi untuk mengukur percepatan, mendeteksi dan mengukur getaran (vibrasi), ataupun untuk mengukur percepatan akibat gravitasi bumi (inklinasi). Sensor accelerometer mengukur percepatan akibat gerakan benda yang melekat padanya. Accelerometer dapat digunakan untuk mengukur getaran yang terjadi pada kendaraan, bangunan, mesin, instalasi pengamanan, dan juga bisa digunakan untuk mengukur getaran yang terjadi pada jembatan, getaran mesin, jarak yang dinamis, dan kecepatan dengan ataupun tanpa pengaruh gravitasi bumi. sensor getar yang digunakan merupakan sensor Accelerometer dengan tipe ADXL345. vibrasi motor (Vibration of Motor) diartikan sebagai gerakan bolakbalik dari motor secara utuh atau komponen mekanik motor sebagai reaksi dari adanya gaya yang mempengaruhinya baik itu gaya dalam maupun gaya luar. Kasus yang dominan terjadi dalam vibrasi motor adalah yang disebabkan oleh gaya eksitasi yang berasal dari motor itu sendiri.

Komponen elektronika daya merupakan komponen yang sangat penting, dimana mampu mengkonversi besaran listrik dari searah menjadi besaran listrik bolak-balik dan sebaliknya, juga untuk mengatur frekuensi yang diharapkan, dan lain sebagainya. Alat pendeteksi getaran pada bantalan motor induksi menggunakan beberapa komponen elektronik seperti IC, kapasitor, resistor dan sensor. Otak sistem adalah sebuah rangkaian kontroler terprogram dari keluarga AVR yaitu Atmega 8, Sedangkan indera sistem adalah sensor piezoelectric, Untuk komunikasi sms digunakan SIM800L yang bekerja mengirimkan pesan sms besaran getaran yang terdeteksi oleh sensor. Agar sistem dapat direalisasikan, kontroler atmega 8 membutuhkan perangkat lunak untuk menjalankan perintah yang dibuat misalnya membaca sensor, Mengkalibrasi hingga mengirim sms. Perangkat lunak dapat dibuat dengan coding bahasa $\mathrm{C}$ yang diedit dengan code vision AVR yaitu program untuk menulis algoritma sekaligus sebagai kompiler algoritma yang dibuat.

\section{TINJAUAN PUSTAKA}

\section{Motor Induksi}

Motor Induksi terdiri atas dua komponen utama yaitu bagian yang diam yang disebut stator dan 
bagian yang berputar yang disebut rotor. Antara rotor dan stator dipisahkan oleh celah udara (air gap) yang kecil dengan jarak antara $0,4 \mathrm{~mm}-4 \mathrm{~mm}$, tergantung daya output motor. Rotor merupakan elemen yang berputar, pada rotor terdapat kutub magnet dengan belitan kawatnya yang dialiri arus. Sedangkan bantalan (bearing) pada kedua sisi poros rotor berfungsi agar rotor dapat berputar bebas di dalam stator.

\section{Bantalan}

Bantalan adalah pendukung gerakan pada poros yang sangat besar perannya dalam operasi kerja motor induksi. Seperti yang telah disebutkan sebelumnya bahwa setiap desain motor induksi memiliki spesifikasi dalam bentuk dan posisi masing- masing komponen. Demikian juga halnya dengan bantalan, banyak sekali desain motor induksi yang meletakkan bantalan pada berbagai posisi, hal ini disesuaikan dengan fungsi utamanya yaitu mendukung gerakan relatif poros.

Jika dijabarkan lebih lanjut definisi vibrasi atau getaran adalah gerakan yang berulang-ulang dengan tempo yang cepat. contoh yang paling sederhana dari vibrasi adalah pendulum yang berayun, senar gitar yang dipetik dsb. Jadi secara bahasa definisi vibrasi motor adalah gerakan yang berulang-ulang dengan tempo yang cepat pada motor. Secara istilah, vibrasi motor (Vibration of Motor) diartikan sebagai gerakan bolak-balik dari motor secara utuh atau komponen mekanik motor sebagai reaksi dari adanya gaya yang mempengaruhinya baik itu gaya dalam maupun gaya luar. Kasus yang dominan terjadi dalam vibrasi motor adalah yang disebabkan oleh gaya eksitasi yang berasal dari motor itu sendiri.[2]

\section{Komponen Elektronika}

Komponen elektronika daya merupakan komponen yang sangat penting, dimana keberadaan komponen elektronika daya inilah yang mampu untuk mengkonversi besaran listrik dari searah menjadi besaran listrik bolak-balik dan sebaliknya, juga untuk mengatur frekuensi yang diharapkan, dan lain sebagainya.

Sensor getaran merupakan salah satu sensor yang dapat mengukur getaran suatu benda yang nantinya dimana data tersebut akan diproses untuk kepentingan percobaan ataupun digunakan untuk mengantisipasi sebuah kemungkinan adanya bahaya. Salah satu jenis sensor getaran yang saat ini sering digunakan adalah accelerometer, alat ini merupakan alat yang dapat berfungsi untuk mengukur percepatan dari sebuah benda. Percepatan tersebut di ukur bukan dengan menggunakan koordinat dari percepatan tersebut, melainkan dengan mengukur percepatan berdasarkan fenomena pergerakan benda yang di hubungkan dengan perubahan massa yang terjadi di dalam alat pengukur tersebut.

Accelerometer adalah sebuah alat yang berfungsi untuk mengukur percepatan, mendeteksi dan mengukur getaran (vibrasi), ataupun untuk mengukur percepatan akibat gravitasi bumi (inklinasi). Sensor accelerometer mengukur percepatan akibat gerakan benda yang melekat padanya. Accelerometer dapat digunakan untuk mengukur getaran yang terjadi pada kendaraan, bangunan, mesin, instalasi pengamanan, dan juga bisa digunakan untuk mengukur getaran yang terjadi pada jembatan, getaran mesin, jarak yang dinamis, dan kecepatan dengan ataupun tanpa pengaruh gravitasi bumi.

Model single-axis dan multi-axis dari sebuah sensor getaran accelerometer dapat mendeteksi besar dan arah dari getaran yang akan diukur, sebagai sebuah kuantitas garis vektor, dan dapat digunakan untuk merasakan arah getaran, percepatan koordinat, dan getaran. sensor getar yang digunakan merupakan sensor Accelerometer dengan tipe ADXL345.

\section{A. Catu Daya}

Power supply atau catu daya ini digunakan sebagai penyedia tegangan atau sumber daya untuk peralatan elektronika dengan prinsip mengubah tegangan listrik yang tersedia dari jaringan distribusi transmisi listrik ke level yang diinginkan sehingga berimplikasi pada pengubahan daya listrik.

\section{B. Buzzer}

Buzzer adalah sebuah komponen eleektronika yang berfungsi untuk mengubah getaran listrik menjadi getaran suara.Buzzer terdiri dari kumparan yang terpasang pada diafragma dan kemudian kumparan tersebut dialiri arus sehingga menjadi electromagnet, Buzzer biasanya digunakan sebagai indikator bahwa proses telah selesai atau terjadi suatu kesalah pada sebuah alat (alarm).

\section{Rangkaian Kontrol}

Buzzer adalah sebuah komponen elektronika yang berfungsi untuk mengubah getaran listrik menjadi getaran suara. Buzzer terdiri dari kumparan yang terpasang pada diafragma dan kemudian kumparan tersebut dialiri arus sehingga menjadi electromagnet, Buzzer biasanya digunakan sebagai indikator bahwa proses telah selesai atau terjadi suatu kesalah pada sebuah alat (alarm).

\section{Mikrokontroler AVR Atmega8}

AVR merupakan salah satu jenis mikrokontroler yang di dalamnya terdapat berbagai macam fungsi. Perbedaannya pada mikro yang pada umumnya digunakan seperti MCS51 adalah pada AVR tidak perlu menggunakan oscillator eksternal karena di dalamnya sudah terdapat internal oscillator. Selain itu kelebihan dari AVR adalah memiliki Power-On 
Reset, yaitu tidak perlu ada tombol reset dari luar karena cukup hanya dengan mematikan supply, maka secara otomatis AVR akan melakukan reset. Untuk beberapa jenis AVR terdapat beberapa fungsi khusus seperti ADC, EEPROM sekitar 128 byte sampai dengan 512 byte. AVR ATmega 8 adalah mikrokontroler CMOS 8-bit berarsitektur AVR RISC yang memiliki $8 \mathrm{~K}$ byte in-System Programmable Flash. Mikrokontroler dengan konsumsi daya rendah ini mampu mengeksekusi instruksi dengan kecepatan maksimum 16MIPS pada frekuensi $16 \mathrm{MHz}$. Jika dibandingkan dengan ATmega8L perbedaannya hanya terletak pada besarnya tegangan yang diperlukan untuk bekerja. Untuk ATmega8 tipe L, mikrokontroler ini dapat bekerja dengan tegangan antara 2,7 - 5,5 V sedangkan untuk ATmega8 hanya dapat bekerja pada tegangan antara 4,5-5,5 V.

\section{Memori AVR Atmega 8}

Memori atmega terbagi menjadi tiga yaitu :

1. Memori Flash

2. Memori Data

3. EEPROM

\section{Timer/Counter 0}

Timer/Country 0 adalah sebuah timer/counter yang dapat mencacah sumber pulsa/clock baik dari dalam chip (timer) ataupun dari luar chip (counter) dengan kapasitas 8-bit atau 256 cacahan. Timer/counter dapat digunakan untuk :

1. Timer/counter biasa

2. Clear Timer on Compare Match (selain Atmega 8)

3. Generator frekuensi (selain Atmega 8)

4. Counter pulsa eksternal

\section{Komunikasi Serial Pada Atmega 8}

Mikrokontroler AVR Atmega 8 memiliki Port USART pada Pin 2 dan Pin 3 untuk melakukan komunikasi data antara mikrokontroler dengan mikrokontroler ataupun mikrokontroler dengan komputer. USART dapat difungsikan sebagai transmisi data sinkron, dan asinkron. Sinkron berarti clock yang digunakan antara transmiter dan receiver satu sumber clock. Sedangkan asinkron berarti transmiter dan receiver mempunyai sumber clock sendiri-sendiri. USART terdiri dalam tiga blok yaitu clock generator, transmiter, dan receiver.

1. USART transmiter

2. USART receiver

\section{METODE}

Alat deteksi pada bantalan motor induksi. Terdiri dari bagian input, proses dan bagian output. Sensor getar bekerja sebagai input yang mengubah getaran fisik menjadi getaran tegangan. Sensor diletakan pada bagian body luar rumah bantalan motor, sensor akan mendeteksi getaran fisik yang dihasilkan dari bantalan motor. Sensor piezoelektrik akan mengubah getaran fisik menjadi getaran tegangan dan diberikan pada bagian pemroses yaitu kontroler Atmega 8, kontroler sebagai bagian pemroses data akan mengindetifikasi hasil deteksi getaran. Jika getaran terdeteksi maka kontroler akan segera mengaktifkan sirene, Pada saat itu juga sms akan dikirim ke operator maintenance. Untuk rangkaian output adalah sirene dan gsm modem yang memberikan hasil deteksi getaran pada bantalan motor.

1. Proses inilisasi dari nilai awal yaitu input harus diketahui untuk menghentikan proses rangkaian sistem deteksi getaran bantalan motor sensor dari piezoelektrik dan outputnya sirene dan modem

2. Untuk Baca sensor getar digunakan sensor piezoelektrik yang ditempelkan pada bagian luar rumah bantalan motor induksi

3. Kontrol Atmega 8 memperkuat sinyal getaran yang dihasilkan dari sensor piezoelektrik dikonversi dan dikalibrasi untuk mengaktifkan sirene dan modem

4. Nilai getaran diprogram diatas $500 \mathrm{~Hz}$ yang dapat dibaca sensor piezoelektrik

5. Mengaktifkan sirene Buzzer berfungsi sebagai pemberi informasi atau peringatan melalui suara. Suara yang sirene atau alarm dengan kekuatan yang cukup besar sehingga dapat mancapai jarak yang cukup jauh

6. Moden GSM mengirinkan pesan melalui jaringan gsm yaitu sms. Modem menggunakan simcard dari operator tertentu untuk operasi komunikasi data dalam proses pengiriman pesan sms

7. SMS diterima oleh operator

Metode penelitian ini dilakukan secara sistematik agar mendapatkan alur kerja yang baik, dan dijabarkan menjadi beberapa langkah, yaitu:

a) Studi literatur dilakukan untuk membantu peneliti menelusuri teori -teori yang sedang berkembang mengenai getaran ditimbulkan bantalan pada motor induksi

b) Pemilihan objek penelitian dilakukan untuk memudahkan peneliti dalam pengklasifikasian motor induksi yang digunakan dalam pengujian

c) Menentukan variabel yang akan diproses, untuk mengerjakan pola pengelompokan peneliti memilih jenis motor induksi yang digunakan variabel kapasitas daya dan umur bantalan terdiri dari:

1. Motor induksi $1440 \mathrm{rpm}(11 \mathrm{~kW})$ dan umur bantalan 5 bulan

2. Motor Induksi $2930 \mathrm{rpm}(15 \mathrm{~kW})$ dan umur bantalan 6 bulan 
3. Motor Induksi $3550 \mathrm{rpm}(22 \mathrm{Kw})$ dan umur bantalan 5 bulan

Tabel.1 Bantalan motor induksi 3 phasa menggunakan perbandingan kondisi pemakaian bantalan

\begin{tabular}{|c|c|c|c|}
\hline $\begin{array}{c}\text { Motor 3 } \\
\text { Phasa }\end{array}$ & Rpm & $\begin{array}{c}\text { Kondisi pemakaian } \\
\text { Bantalan motor( } \\
\text { Bulan ) }\end{array}$ & $\begin{array}{c}\text { Kondisi } \\
\text { pemakaian } \\
\text { Bantalan motor } \\
\text { (Bulan ) }\end{array}$ \\
\hline $11 \mathrm{Kw}$ & 1440 & 6 & 11 \\
\hline $15 \mathrm{Kw}$ & 2200 & 6 & 12 \\
\hline $22 \mathrm{Kw}$ & 3550 & 7 & 12 \\
\hline
\end{tabular}

\section{HASIL DAN PEMBAHASAN}

Hasil penelitian adalah sebuah sistem deteksi getaran pada bantalan motor berbasis sensor getar, rancangan dibuat dengan beberapa komponen seperti dibahas pada bab sebelumnya. alat deteksi getaran dibuat agar praktis dan mudah digunakan sebagai alat untuk mendeteksi adanya gangguan getaran pada bantalan motor. Sebuah kontroler avr digunakan untuk mengolah data sensor dan mengaktifkan alarm serta mengirim sms. sensor sendiri bekerja mendeteksi getaran pada bantalan motor dengan alat piezoelectrik yang memiliki sensitifitas cukup tinggi. adapun kelemahan alat yang ditemukan adalah adanya gangguan yang mempengaruhi kinerja system, misalnya start awal getaran motor saat dihidupkan, namun getaran yang terdeteksi adalah getaran sesaat start awal motor dihidupkan yang diketahui operator maintenance, Langkah berikut adalah prosedur pengujian dan hasilnya berupa data.

Berikut ini adalah Tabel hasil deteksi getaran pada bantalan motor induksi, pengujian alat deteksi getaran menggunakan Sensor Piezoelektrik dan Motor induksi 3 phasa dengan kapasitas daya $(\mathrm{Kw})$ dan putaran motor (Rpm) yang berbeda, dengan perbandingan kondisi pemakaian motor dalam hitungan Bulan. Adapun hasil getaran dapat dilihat pada Tabel 2.

Tabel 2.Hasil pengujian deteksi getaran pada bantalan motor induksi 3 phasa menggunakan perbandingan kondisi pemakaian bantalan

\begin{tabular}{|c|c|c|c|c|c|}
\hline $\begin{array}{c}\text { Motor 3 } \\
\text { Phasa }\end{array}$ & Rpm & $\begin{array}{c}\text { Kondisi } \\
\text { pemakaian } \\
\text { bantalan } \\
\text { motor ( } \\
\text { Bulan })\end{array}$ & $\begin{array}{c}\text { Hasil } \\
\text { Getaran } \\
(\mathrm{Hz})\end{array}$ & $\begin{array}{c}\text { Kondisi } \\
\text { pemakaian } \\
\text { bantalan } \\
\text { motor } \\
(\text { Bulan })\end{array}$ & $\begin{array}{c}\text { Hasil } \\
\text { Getaran } \\
(\mathrm{Hz})\end{array}$ \\
\hline $11 \mathrm{Kw}$ & 1440 & 6 & 327 & 11 & 746 \\
\hline $15 \mathrm{Kw}$ & 2200 & 6 & 478 & 12 & 895 \\
\hline $22 \mathrm{Kw}$ & 3550 & 7 & 562 & 12 & 1023 \\
\hline
\end{tabular}

Modem gsm harus diuji dengan program yaitu program yang dibuat untuk mengirim suatu pesan sms. Setelah itu jalankan program tersebut pada kontroler, Jika berhasil maka sms akan terkirim ke nomor ponsel yang dituju. Untuk pengujian ini dibuat program sebagai berikut:

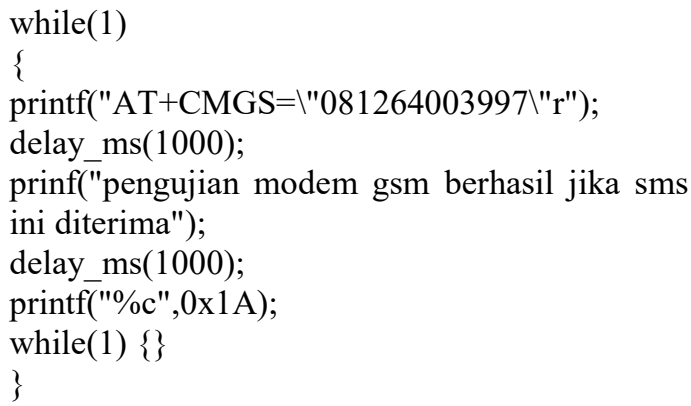

Setelah program diatas di susun dan diunggah pada kontroler atmega 8 kemudian dijalankan. saat pertama kali sms tidak terkirim karena tidak masuk ke ponsel yang dituju. setelah diperiksa dan diperbaiki sedemikian rupa dan diuji kembali, sms baru terkirim ke ponsel penerima. Kesalahan pertama adalah antena tidak terpasang karenanya modem tidak mendapat sinyal gsm. Selain itu kualitas sinyal gsm juga sangat mempengaruhi proses pengiriman sms. Jika kualitas kurang baik maka akan terjadi delay atau tundaan waktu pengiriman.

Pengujian program dilakukan untuk melihat apakah driver dan relay berjalan sesuai dengan yang diinginkan atau tidak. Tahap pertama pengujian adalah melihat pengaruh tegangan masuk terhadap relay. Hasil pengujian menunjukkan, saat diberi logika 1 pada basis driver transistor maka relay akan on dan mengaktifkan buzzer atau sirene. Kemudian saat tegangan keluaran dari basis transistor bernilai low, maka akan mematikan relay akan off dan sirene akan diam. Pengujian ini dilakukan dengan multimeter yang dihubungkan ke ground dan port tegangan masukan atau basis transistor. Hasil tegangan keluaran dari mikrokontroler ke basis transistor untuk dapat membuat relay aktif dapat dilihat pada Tabel 3 .

Tabel 3 Memperlihatkan bahwa tegangan pada basis transistor harus $\geq 0,7$ volt untuk dapat mengaktifkan relay. Sedangkan untuk tegangan $\leq 0,7$ volt tidak dapat mengaktifkan relay.

\begin{tabular}{|c|c|c|}
\hline No & Tengan sensor (Volt) & Kondisi Relay \\
\hline 1 & 0.45 & Tidak aktif \\
\hline 2 & 0.57 & Tidak aktif \\
\hline 3 & 0.71 & Aktif \\
\hline 4 & 0.80 & Aktif \\
\hline
\end{tabular}


Pengujian alat secara keseluruhan dilakukan untuk melihat apakah alat secara keseluruhan sudah berjalan sesuai dengan yang diinginkan atau tidak. Alat ini dirancang dengan efektifitas pengguna yang mudah dan praktis. Dalam pengujian keseluruhan ini digunakan Beberapa Motor induksi yang memiliki daya dan putaran setiap motor $11 \mathrm{Kw} 1440 \mathrm{Rpm}, 15$ Kw 2930 Rpm, 22 Kw 3550 Rpm. Pengujian dilakukan menggunakan perbandingan kondisi pemakaian bantalan dalam hitungan bulan dari setiap motor induksi,

Dari tabel 4 dapat dilihat bahwa Buzer aktif jika adanya getaran yang dideteksi oleh sensor pada setiap Bantalan Motor Induksi dan sms terkirim ke ponsel operator maintenance motor untuk mengetahui seberapa besar hasil nilai getaran pada setiap Bantalan Motor Induksi yang dideteksi oleh sensor. Dari hasil pengujian ini dapat dibuktikan bahwa alat deteksi getaran pada Bantalan Motor Induksi, telah bekerja dengan baik sesuai dengan yang diharapkan. Oleh karena itu dapat disimpulkan alat deteksi getaran pada Bantalan Motor Induksi menggunakan metode seperti ini berhasil dibuat atau direalisasikan pada suatu Industri.

Tabel 4. Hasil pengujian sistem alat secara keseluruhan

\begin{tabular}{|l|c|c|c|c|c|c|c|}
\hline Motor & Rpm & $\begin{array}{c}\text { Kondisi } \\
\text { pemakaian } \\
\text { bantalan } \\
\text { motor } \\
\text { ( Bulan) }\end{array}$ & $\begin{array}{c}\text { Hasil } \\
\text { getaran } \\
\text { ( Hz })\end{array}$ & $\begin{array}{c}\text { Kondisi } \\
\text { pemakaian } \\
\text { bantalan } \\
\text { motor } \\
\text { ( Bulan ) }\end{array}$ & $\begin{array}{c}\text { Hasil } \\
\text { getaran } \\
\text { ( Hz })\end{array}$ & $\begin{array}{c}\text { Kondisi } \\
\text { buzzer }\end{array}$ & Sms \\
\hline $11 \mathrm{kw}$ & 1140 & 6 & 327 & 11 & 746 & Aktif & Ada \\
\hline $15 \mathrm{kw}$ & 2930 & 6 & 478 & 12 & 895 & Aktif & Ada \\
\hline $22 \mathrm{kw}$ & 3550 & 7 & 562 & 12 & 1023 & Aktif & Ada \\
\hline
\end{tabular}

\section{KESIMPULAN}

Adapun kesimpulan dari penilitian adalah Tegangan pada basis transistor harus $\geq 0,7$ volt untuk dapat mengaktifkan relay. Sedangkan untuk tegangan $\leq 0,7$ volt tidak dapat mengaktifkan relay. Getaran yang telah dideteksi oleh sensor piezoelektrik pada motor induksi dengan $1440 \mathrm{rpm}(11 \mathrm{~kW})$ nilai getarannya $327 \mathrm{~Hz}$ umur bantalan 6 bulan dan 746 $\mathrm{Hz}$ pemakaian bantalan 11 bulan. Getaran yang telah dideteksi oleh sensor piezoelektrik pada motor induksi dengan $2930 \mathrm{rpm}$ ( $15 \mathrm{k}$ nilai getarannya $478 \mathrm{~Hz}$ umur bantalan 6 bulan dan $895 \mathrm{~Hz}$ umur bantalan 12 bulan. Getaran yang telah dideteksi oleh sensor piezoelektrik pada motor induksi dengan $3550 \mathrm{rpm}$ ( $22 \mathrm{~kW}$ ) nilai getarannya $562 \mathrm{~Hz}$ umur bantalan 7 bulan dan $1023 \mathrm{~Hz}$ umur bantalan 12 bulan. Alat deteksi getaran pada Bantalan Motor Induksi menggunakan metode seperti ini berhasil dibuat atau direalisasikan pada suatu Industri.

\section{DAFTAR PUSTAKA}

[1] Sumanto,' 'Motor Litrik Arus Bolak-balik,' Andi Offset Yogyakarta, Edisi pertama, 1993. Mcconnel, Kenneth G., Vibration Testing, New York (1995): John Wiley \& Sons,Inc.

[2] Serridge, Mark. Torben R. Licht.1987. Piezoelectric Accelerometer and Vibration Preamplifier Handbook, Bruel \& Kjaer.

[3] Richard Blocher 2009, Dasar Elektronika, Penerbit Andi, Jogyakarta.

[4] Jazi Eko Istiyanto 2013, Pengantar Elektronika \& Instrumentasi, Penerbit Andi, Jogyakarta.

[5] Sugiri, A. Md., S.Pd, 2008, Elektronika Dasar \& Peripheral Komputer, Penerbit Andi, Jogyakarta.

[6] Mohammad Mohsin, ST., 2004 Elektronika Digital teori dan penyelesaian soal, Penerbit Andi, Jogyakarta.

[7] Syahban Rangkuti 2011, Mikrokontroler ATMEL AVR (ISIS Proteus dan CodeVisionAVR) + CD : INFORMATIKA, Jakarta.

[8] Lingga Wardhana, 2007, Mikrokontroler AVR seri Atmega 8535, Penerbit Andi, Jogyakarta.

[9] Dayat Kurniawan 2010, Aplikasi elektronika dengan bahasa C, Elex media Komputindo, Jakarta.

[10] Andi winoto 2006, Balajar Miikrokontroler Atmel AVR ATtiny 2313 step by step, penerbit Gaya Media Yogyakarta.

[11] Indra Roza 2018, Analisis Arus StartMotor 3 Fhasa pada Boiler Feed Water Pump (BFWP) Unit 1 PLTU Labuhan Angin Dalam Aplikasi Etap Seminar Nasional Teknik (SEMNASTEK) 154 (Fakultas Teknik UISU 2018), 114-120 Medan.

[12] SH, Indra Roza, Junaidi, Faisal Irsan Pasaribu, Weriono 2018, Economic Planning Analysis of MHP PLTMH using Pico-Hydro Turbine: Hundreds of watts - $5 \mathrm{KW}$, International Journal of Innovative Sc 